\title{
Measurement Techniques for Evaluating Encapsulant Thermophysical Properties During Cure
}

Douglas Adolf

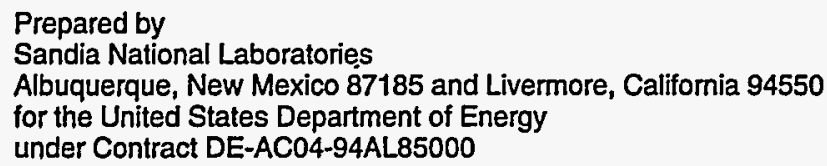

Approved for public release, distribution is unlimited. 
Issued by Sandia National Laboratories, operated for the United States Department of Energy by Sandia Corporation.

NOTICE: This report was prepared as an account of work sponsored by an agency of the United States Government. Neither the United States Government nor any agency thereof, nor any of their employees, nor any of their contractors, subcontractors, or their employees, makes any warranty, express or implied, or assumes any legal liability or responsibility for the accuracy, completeness, or usefulness of any information, apparatus, product, or process disclosed, or represents that its use would not infringe privately owned rights. Reference herein to any specific commercial product, process, or service by trade name, trademark, manufacturer, or otherwise, does not necessarily constitute or imply its endorsement, recommendation, or favoring by the United States Government, any agency thereof or any of their contractors or subcontractors. The views and opinions expressed herein do not necessarily state or reflect those of the United States Government, any agency thereof or any of their contractors.

Printed in the United States of America. This report has been reproduced directly from the best available copy.

Available to DOE and DOE contractors from Office of Scientific and Technical Information PO Box 62

Oak Ridge, TN 37831

Prices available from (615) 576-8401, FTS 626-8401

Available to the public from

National Technical Information Service

US Department of Commerce

5285 Port Royal Rd

Springfield, VA 22161

NTIS price codes

Printed copy: A03

Microfiche copy: A01 
SAND 96-1458

Unlimited Release

Printed June 1996

\title{
Measurement Techniques for Evaluating Encapsulant Thermophysical Properties During Cure
}

\author{
Douglas Adolf \\ Theoretical and Computational Materials Modelling Department \\ Sandia National Laboratories \\ Albuquerque, NM 87185
}

\begin{abstract}
$\underline{\text { Abstract }}$
Sandia now has the capability to evaluate stresses during the cure of epoxies with finite element codes. Numerous material parameters are needed as input to these codes. I present a relatively quick set of tests which enable the evaluation of the required thermophysical properties. The ease and accuracy of the tests improve as the reaction rate of the thermoset slows. Material parameters for common encapsulants at Sandia are presented in the tables attached.
\end{abstract}

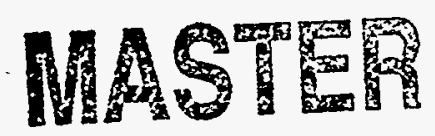




\section{Introduction}

We have previously developed a formalism which enables us to relate the changing viscoelasticity of curing thermosets to extent of reaction. 1 These relationships have been incorporated into finite element (FEA) codes which, in turn, enable us to calculate stress during encapsulant cure and viscosity rise during processing. We are now in a position to calculate the optimal time/temperature history for cure that minimizes stress and for mixing/degassing that maximizes pot life.

As expected, there are numerous thermophysical properties required as input to the FEA codes. These properties are listed in Tables 1-3 for several Sandia encapsulants. Since, as stated above, we relate cure dependent properties to extent of reaction, we also require expressions for the rate of reaction. These expressions are presented in Table 4 for the same encapsulants. Note that the 828/DEA encapsulation system exhibits extremely unusual reaction kinetics. These phenomenological equations are correct; DEA is not a typical curing agent.

\section{Definition of Terms}

While the numerical values of the FEA code inputs are tabulated in the attached tables, it is imperative to clearly define the terms. A detailed description of each term was presented previously. ${ }^{1}$ Here, a concise definition of each is given.

First, we have a set of five thermal parameters. $C_{p}$ glassy and $\mathrm{C}_{\mathrm{p}}$ rubbery are the constant pressure heat capacities per unit weight of the encapsulant below and above the glass transition respectively. $k_{\text {th }}$ is the thermal conductivity and $\rho$ is the mass density. Finally, $\Delta \mathrm{H}_{\mathrm{rxn}}$ is the total heat of reaction.

For thermosets, our studies have indicated that the shear and bulk spectra of relaxation times are invariant from system to system. ${ }^{2}$ Therefore, we require only the four limiting values of the 


\section{DISCLAIMER}

Portions of this document may be illegible in electronic image products. Images are produced from the best available original document. 


\section{DISCLAIMER}

This report was prepared as an account of work sponsored by an agency of the United States Government. Neither the United States Government nor any agency thereof, nor any of their employees, makes any warranty, express or implied, of assumes any legal liability or responsibility for the accuracy, completeness, or usefulness of any information, apparatus, product, or process disclosed, or represents that its use would not infringe privately owned rights. Reference herein to any specific commercial product, process, or service by trade name, trademark, manufacturer, or otherwise does not necessarily constitute or imply its endorsement, recommendation, or favoring by the United States Government or any agency thereof. The views and opinions of authors expressed herein do not necessarily state or reflect those of the United States Government or any agency thereof. 
moduli. $\mathrm{G}_{\mathrm{g}}$ and $\mathrm{K}_{\mathrm{g}}$ are the shear and bulk moduli well below the glassy transition, while $G_{\infty}$ and $K_{\infty}$ are the shear and bulk moduli well above this transition. We neglect the absolute temperature dependence of all these parameters. The equilibrium shear modulus, $G_{\infty}$ increases with extent of reaction ( $p$ ) becoming non-zero at the gel point ( $p_{\text {gel }}$ ) and increasing to $G_{\infty}{ }^{f}$ at the completion of the reaction $(p=1)$. We can theoretically predict this rise in equilibrium modulus with cure, ${ }^{3}$ so the only parameter needed is the ultimate value, $G_{\infty}{ }^{f}$.

Since all systems investigated are thermorheologically simple, we also must define the "WLF" parameters, ${ }^{4} C_{1}$ and $C_{2}$. In addition, we have discovered that epoxies exhibit a cure-time superposition 5 principle analogous to the well-known time-temperature superposition. These two shifting operations can be combined into one relation for the shortest relaxation time, $\tau$, where $\log \tau=$ $-C_{1}\left(T-T_{g}\right) /\left(C_{2}+T-T_{g}\right)$. Note that we have defined the glass transition temperature, $\mathrm{T}_{\mathrm{g}}$, as the temperature at which the shortest relaxation time, $\tau$, equals one second. This relationship implies that we must track the increase in $T_{g}$ with extent of reaction, which introduces three additional parameters, $\mathrm{T}_{\mathrm{g}}{ }^{\circ}, \mathrm{A}$, and $\mathrm{B}$, where $\mathrm{T}_{\mathrm{g}}=$ $\mathrm{T}_{\mathrm{g}} \mathrm{o} /(1-\mathrm{Ap}) /\left(1-B G_{\infty} / G_{\infty}{ }^{f}\right) . \mathrm{T}_{\mathrm{g}}{ }^{\circ}$ is simply the $\mathrm{T}_{\mathrm{g}}$ of the intial reactants prior to the start of the reaction in degrees Kelvin. A defines the increase in $T_{g}$ with increasing extent of reaction whereas $B$ defines the increase in $T_{g}$ with increasing equilibrium modulus.

In order to describe the increase in viscosity with extent of reaction, we need only the viscosity of the initial reactants, $\eta_{0}{ }^{\mathrm{Tg}}$, at a given temperature, chosen to be $T_{g}$ for consistency with the above. We can theoretically predict the increase with reaction. ${ }^{6}$ The reaction does not significantly affect the chemical nature of the encapsulant so that the temperature dependence of the reactant viscosity can be described by the crosslinked WLF parameters defined above. Note that the reference temperature, $T_{g}$, must still be appropriate for the current extent of reaction. We have assumed also that the system is 
Newtonian. All unfilled thermosets exhibit Newtonian behavior under reasonable processing conditions. However, our filled systems are distinctly non-Newtonian making the prediction of the increase in "apparent" viscosity much more difficult and non-universal.

We have only three additional parameters to introduce, $\Psi, \Phi$, and $\omega . \Psi$ represents the stress increment due to an increment in temperature, while $\Phi$ represents the stress increment due to an increment in extent of reaction. $\Psi$ approximately equals the product of the glassy bulk modulus and the glassy coefficient of thermal expansion, $\mathrm{K}_{\mathrm{g}} \alpha_{\mathrm{g}}{ }^{7}$ while $\Phi$ approximately equals the product of the rubbery bulk modulus and the total volumetric cure shrinkage,

$\mathrm{K}_{\infty} \Delta_{\mathrm{V} \text {, cure }}$. The final parameter, $\omega$, is more difficult to describe. As the reaction progresses, the glass transition temperature rises, and in many curing operations, $\mathrm{T}_{\mathrm{g}}$ actually exceeds the curing temperature. At this point, the reaction rate dramatically slows due to vitrification, but some further reaction will proceed. $\omega$ defines how quickly the reaction is quenched by this vitrification.

\section{Procedures for Parameter Evaluation}

The techniques presented below can be quite simple for an encapsulant system with slow kinetics and a relatively low $\mathrm{T}_{\mathrm{g}}$ of the fully cured thermoset. In this limit, we can raise the experimental temperature to avoid difficulties associated with vitrification during cure without severely increasing our reaction rate so that we still maintain a comfortable amount of time in which to perform these experiments. For encapsulants with high $\mathrm{T}_{g}$ 's and fast kinetics, we can be faced with the prospect of needing low temperatures so that the reaction slows down enough to allow measurements, but which then vitrifies at a relatively low extent of reaction. Fortunately, Sandia typically uses epoxies to encapsulate relatively large components. Therefore, we cannot use fast reacting systems that release heat quickly, hold it, and generate large temperature rises in 
the interior of components. Our encapsulants are sluggish. In industrial applications such as microelectronics with small components and high throughput, however, the situation is reversed. Here, time is money, and the reaction kinetics are very fast and the $T_{g}$ 's are typically quite high. These systems would be much more difficult to characterize than ours. In the following, I will present a path to evaluate the parameters required for our analyses based on the assumption that the kinetics are not exceedingly fast. Obviously, each thermoset will be a bit different, and the path must be viewed as a general guide.

First, let's discuss the chemical kinetics. The simplest procedure is to relate the reaction rate, $\mathrm{dp} / \mathrm{dt}$, to the instantaneous heat output, $\mathrm{dH} / \mathrm{dt}$, as measured by isothermal differential scanning calorimetry (DSC). The total heat of reaction, $\Delta \mathrm{H}_{\mathrm{rxn}}$ is simply the integral of the measured curve, and $\mathrm{dp} / \mathrm{dt}=(\mathrm{dH} / \mathrm{dt}) / \Delta \mathrm{H}_{\mathrm{rxn}}$. The isothermal rate must be measured at several temperatures in the range of interest. One must also be aware of vitrification during cure, which will invalidate measurements of at least part of the rate and perhaps the total heat (depending on the severity of the effect).

Near reaction completion, determination of extent of reaction by DSC becomes difficult due to uncertainties in the zero-point. Unfortunately, stresses generated during this portion of the cure can be important since the equilibrium modulus is largest here. A reasonable approach for this latter stage of reaction is to follow the rise in equilibrium modulus via mechanical spectrometry. By reacting the thermoset directly on the rheometer's parallel plates, one can follow $G^{\prime}$ during the course of the reaction. Near the end of the reaction, $G^{\prime}$ is almost identically $G_{\infty}$ as long as the measurement temperature exceeds the $T_{g}$ of the fully-cured material. From theoretical arguments, the extent of reaction at these late times can. then be related to $G_{\infty} \cdot 3$ 
The extent of reaction at the gel point, $\mathrm{p}_{\text {gel }}$, must now be determined. We have tried various methods to find $\mathrm{p}_{\text {gel }}$, but the "poke test" is by far the easiest. This test consists of simply poking a curing epoxy with a stick. The gel point is clearly defined by an unmistakable and rapid increase in the "elasticity" (actually viscoelasticity) of the sample. By correlating the gel time to the extent of reaction determined from DSC, one now knows $\mathrm{p}_{\text {gel }}$. The only possible source of confusion arises if the cure temperature is so low that the sample vitrifies before it gels. In this case, the viscoelasticity associated with $\mathrm{T}_{\mathrm{g}}$ can cloud the gel point. In the process of determining the gel point, an extra sample can be gelling. When the gel point is detected, the extra sample can be quenched in a refrigerator. At a later time, one can determine the $T_{g}$ at the gel point by thermomechanical analysis (TMA) from which the constant A can be calculated.

The bulk moduli limits, $\mathrm{K}_{\mathrm{g}}$ and $\mathrm{K}_{\infty}$, as well as the glassy coefficient of thermal expansion, $\alpha_{g}$, can be found by dilatometry. In this experiment, we simply measure the pressure dependence of the specific volume for a fully-cured sample at different temperatures. An accurate measurement of the specific volume (or, equivalently, density, $\rho$ ) at atmospheric pressure and room temperature is needed as an initial condition. A relatively accurate and painless technique involves cutting a sample to known dimensions and weighing. If dilatometry is deemed too time-consuming, these quantities can be fairly accurately estimated.

The shear modulus limits, $G_{g}$ and $G_{\infty}{ }^{f}$, for a fully-cured encapsulant are easily determined by mechanical spectrometry. Frequency sweeps at various temperatures using torsion rectangular geometry will not only yield these limits but the glass transition temerature of the fully-cured sample, $\mathrm{T}_{\mathrm{g}}{ }^{f}$, and the WLF shift factors, $C_{1}$ and $C_{2}$, as well. $T_{g}{ }^{f}$ can be then related to the parameter, $B$, which describes the increase in $\mathrm{T}_{\mathrm{g}}$ with extent of reaction. 
Of the remaining seven parameters, five can be evaluated from relatively easy tests. The $T_{g}$ of the unreacted sample, $T_{g}{ }^{\circ}$, can be directly measured by TMA, although subambient capability is required. The parameter characterizing the viscosity of the unreacted sample at $T_{g}, \eta_{0}{ }^{T g}$, can be found by direct measurement on a parallel plate rheometer at a convenient temperature followed by a shift to $T_{g}$ using the cured sample's WLF parameters. The heat capacity of the fully-cured sample can be measured directly with DSC, or it can probably be estimated with equal accuracy. Finally, $\omega$ can be determined by curing a sample at a relatively low temperature such that it vitrifies before completion. The $\mathrm{T}_{\mathrm{g}}$ of the sample (as measured by TMA) after curing a day or so at this low temperature will be roughly $25^{\circ} \mathrm{C}$ above the cure temperature. By using our theoretical formalism 1 with the correct reaction kinetics, one can determine which value of $\omega$ best fits the measured $T_{g}$.

We are now left with only two parameters to measure, the thermal conductivity, $k_{t h}$, and the total cure shrinkage, $\Delta_{v, \text { cure }}$. Both of these quantities are not easily evaluated. There are welldocumented procedures for determining $k_{\text {th }}$. However, these are not easy nor does Sandia have an established capability. For our purposes, most thermal conductivities for Sandia encapsulants are documented on the "Quant" chart. Moreover, $k_{\text {th }}$ can be fairly accurately predicted for epoxy encapsulants with minor curing agent or filler changes.

In contrast, there are no well-established procedures for determining cure shrinkage. In fact, ASTM tests claiming to measure this quantity are incorrect and misleading. For example, a typical test would involve pouring an epoxy into a mold of a known length, curing at elevated temperature, cooling to room temperature, popping it out of the mold, and measuring its new length. This technique obviously includes not only the cure shrinkage but the shrinkage due to cooldown from the cure temperature in the glassy 
state (heat up was in the rubbery state!). The only correct data for cure shrinkage to date were collected by Plazek. 8 In this test, $828 / D E A$ was cured to the gel point and placed into a heated dilatometer. The volume during cure was directly measured and related to extent of reaction. While this technique could be applied to other slow curing epoxies, the large thermal mass of most dilatometers seems to preclude its application to systems with faster kinetics. The only remaining option would be to use the scarce extant data to estimate the shrinkage of the new epoxy in question.

\section{Time Commitment}

In evaluating the time required to determine these properties, we need to consider not only the test itself, but sample preparation and data analysis as well. Moreover, as stated above, some encapsulants will be intrinsically more difficult. Therefore, these time estimates should be viewed simply as ballpark figures.

Determination of the kinetics via DSC and mechanical spectrometry should take roughly a week to perform, with no sample preparation, but a day of data fitting. TMA runs for determination of the constant $A, T_{g}{ }^{\circ}$, and $\omega$, should require roughly a day to perform with a half day of sample preparation and no post-analysis. The gel point "poke test" and the parallel plate rheometry to determine $\eta_{\circ}$ require roughly one day total. Our experience with dilatometry suggests that determination of $\mathrm{K}_{\mathrm{g}}, \mathrm{K}_{\infty}$, and $\alpha_{\mathrm{g}}$ will require one test day, a half day of sample preparation, and a half day of data reduction. Five frequency/temperature sweeps on the rheometer to determine the shear moduli and shift parameters requires only a half day of sample preparation and a half day of operation. DSC evaluation of heat capacities would require a day total, but could easily be theoretically predicted. Evaluation of the cure shrinkage would involve a half day in sample preparation and one day of 
operation with little post-analysis. Finally the thermal conductivity could require two days total.

In summary, the total time commitment to characterize a new encapsulant is estimated at rougly three weeks. However, this assumes that we are somewhat familiar with the proposed system. For example, we would have a good idea of its cure schedule and ultimate $\mathrm{T}_{g}$. On the other hand, we could fairly rapidly evaluate only key parameters for encapsulants for which a change in filler loading level is proposed and accurately estimate the remainder. Finally, we can immediately play "what if" games by proposing new properties to assess their relative importance to cure stresses.

References

(1) D. Adolf and J. Martin, J. Comp. Mat., 30, 13 (1996).

(2) D. Adolf and J. Martin, Macromol., 24, 6721 (1991).

(3) J. Martin, D. Adolf, and J. Wilcoxon, Phys, Rev. A, 39, 1325 (1989).

(4) J. D. Ferry, Viscoelastic Properties of Polymers, Wiley, NY, 1980.

(5) D. Adolf and J. Martin, Macromol., 23, 3700 (1990).

(6) D. Adolf, J. Martin, and J. Wilcoxon, Macromol., 23, 527 (1990).

(7) D. Adolf, Macromol., 28, 5978 (1995).

(8) R. S. Chambers et al, Proc. ASME/JSME Adv. in Elec. Pack., ASME, 1992. 
Table 1: Material Parameters for Sandia Unfilled Encapsulants

\begin{tabular}{|c|c|c|}
\hline parameter & 828/DEA ${ }^{*}$ & $\underline{828 / Z^{+}}$ \\
\hline$\eta_{\mathrm{o}} \mathrm{Tg}_{\mathrm{g}}(\mathrm{MP})$ & 100 & 20 \\
\hline $\mathrm{K}_{\mathrm{g}}(\mathrm{GPa})$ & 5.1 & 5.3 \\
\hline $\mathrm{K}_{\infty}(\mathrm{GPa})$ & 2.6 & 2.7 \\
\hline $\mathrm{Gg}(\mathrm{GPa})$ & 1.0 & 1.2 \\
\hline $\mathrm{G}_{\infty} \mathrm{f}(\mathrm{MPa})$ & 7.0 & 14 \\
\hline $\mathrm{C}_{1}$ & 14.2 & 12.4 \\
\hline $\mathrm{C}_{2}(\mathrm{oK})$ & 40.4 & 43.8 \\
\hline $\mathrm{Tg}_{\mathrm{g}} \mathrm{o}(\mathrm{oK})$ & 260 & 260 \\
\hline $\mathrm{A}$ & 0.2 & 0.25 \\
\hline $\mathrm{B}$ & 0.067 & 0.25 \\
\hline Pgel & 0.65 & 0.75 \\
\hline$\rho\left(g / \mathrm{cm}^{3}\right)$ & 1.2 & 1.2 \\
\hline$\Psi(\mathrm{MPa} / \mathrm{oK})$ & 0.94 & 0.82 \\
\hline$\Phi(\mathrm{MPa})$ & 140 & 150 \\
\hline Cpglassy (J/goK) & 1.4 & 1.3 \\
\hline $\mathrm{C}_{\mathrm{p}}$ rubbery $(\mathrm{J} / \mathrm{goK})$ & 2.1 & 1.9 \\
\hline$\Delta \mathrm{H}_{\mathrm{rxn}}(\mathrm{J} / \mathrm{g})$ & 200 & 400 \\
\hline $\mathrm{k}_{\mathrm{th}}(\mathrm{W} / \mathrm{m}-\mathrm{oK})$ & 0.16 & 0.17 \\
\hline$\omega$ & $10-8$ & $10-8$ \\
\hline$\Delta_{\mathrm{v}, \text { cure }}$ (post gel only) & 0.019 & 0.014 \\
\hline
\end{tabular}


Table 2: Material Parameters for Sandia Filled Encapsulants parameter $\quad \underline{828-C T B N / D E A / G M B}{ }^{*} \quad \underline{828 / Z / A l o x}{ }^{\dagger}$

\begin{tabular}{|c|c|c|}
\hline $\mathrm{K}_{\mathrm{g}}(\mathrm{GPa})$ & 3.1 & 12 \\
\hline $\mathrm{K}_{\infty}(\mathrm{GPa})$ & 2.0 & 6.0 \\
\hline $\mathrm{Gg}_{\mathrm{g}}(\mathrm{GPa})$ & 1.0 & 5.7 \\
\hline $\mathrm{G}_{\infty} f(\mathrm{MPa})$ & 55 & 75 \\
\hline $\mathrm{C}_{1}$ & 14.2 & 12.4 \\
\hline $\mathrm{C}_{2}(\mathrm{oK})$ & 40.4 & 43.8 \\
\hline $\mathrm{Tg}_{\mathrm{g}} \mathrm{(oK}$ ) & 260 & 260 \\
\hline A & 0.2 & 0.25 \\
\hline B & 0.067 & 0.25 \\
\hline Pgel . & 0.65 & 0.75 \\
\hline$\rho\left(\mathrm{g} / \mathrm{cm}^{3}\right)$ & 0.87 & 2.4 \\
\hline$\Psi(\mathrm{MPa} / \mathrm{oK})$ & 0.44 & 0.95 \\
\hline$\Phi(\mathrm{MPa})$ & 58 & 190 \\
\hline Cpglassy (J/goK) & 1.3 & 1.0 \\
\hline $\mathrm{C}_{\mathrm{p}}$ rubbery $(\mathrm{J} / \mathrm{g} \circ \mathrm{K})$ & 1.8 & 1.2 \\
\hline$\Delta \mathrm{H}_{\mathrm{rxn}}(\mathrm{J} / \mathrm{g})$ & 180 & 120 \\
\hline $\mathrm{k}_{\mathrm{th}}(\mathrm{W} / \mathrm{m}-\mathrm{oK})$ & 0.16 & 0.89 \\
\hline$\omega$ & $10-8$ & $10-8$ \\
\hline$\Delta_{\mathrm{V}, \text { cure }}$ (post gel only) & 0.0099 & 0.0081 \\
\hline
\end{tabular}


Table 3: Material Parameters for a New "Z-Replacement"

\begin{tabular}{|c|c|c|}
\hline parameter & $\underline{459}$ & $\underline{459 / \mathrm{Alox}^{*}}$ \\
\hline$\eta_{\mathrm{o}} \mathrm{Tg}(\mathrm{GPa})$ & 16 & - - \\
\hline $\mathrm{K}_{\mathrm{g}}(\mathrm{GPa})$ & 5.3 & 16 \\
\hline $\mathrm{K}_{\infty}(\mathrm{GPa})$ & 2.7 & 8.0 \\
\hline $\mathrm{Gg}(\mathrm{GPa})$ & 1.2 & 7.6 \\
\hline $\mathrm{G}_{\infty} \mathrm{f}(\mathrm{MPa})$ & 10 & 56 \\
\hline $\mathrm{C}_{1}$ & 12.4 & 12.4 \\
\hline $\mathrm{C}_{2}(\mathrm{oK})$ & 43.8 & 43.8 \\
\hline $\mathrm{Tg}_{\mathrm{g}} \mathrm{oK}$ (oK) & 245 & 245 \\
\hline A & 0.29 & 0.29 \\
\hline B & 0.22 & 0.22 \\
\hline Pgel & 0.865 & 0.865 \\
\hline$\rho\left(g / \mathrm{cm}^{3}\right)$ & 1.1 & 2.4 \\
\hline$\Psi(\mathrm{MPa} / \mathrm{oK})$ & 0.89 & 1.4 \\
\hline$\Phi(\mathrm{MPa})$ & 140 & 220 \\
\hline Cpglassy $(\mathrm{J} / \mathrm{g} \circ \mathrm{K})$ & 1.3 & 1.0 \\
\hline $\mathrm{C}_{\mathrm{p}}$ rubbery $(\mathrm{J} / \mathrm{goK})$ & 1.9 & 1.2 \\
\hline$\Delta \mathrm{H}_{\mathrm{rxn}}(\mathrm{J} / \mathrm{g})$ & 420 & 100 \\
\hline $\mathrm{k}_{\mathrm{th}}(\mathrm{W} / \mathrm{m}-\mathrm{oK})$ & 0.17 & 0.94 \\
\hline$\omega$ & $10^{-8}$ & $10-8$ \\
\hline
\end{tabular}


Table 4: Reaction Kinetics for Common Epoxy Encapsulants 828/DEA for $\mathrm{T} \leq 95^{\circ} \mathrm{C}$

$$
\frac{d p}{d t}=\left(k_{1}+k_{2} p^{m}\right)(1-p)^{1.6} \quad \text { where }
$$

for $\mathrm{T}<95^{\circ} \mathrm{C} \quad \mathrm{k}_{1}=\left(2.6 \times 10^{7} \mathrm{~min}^{-1}\right) \exp \left(-8000^{\circ} \mathrm{K} / \mathrm{T}\right)$

for $\mathrm{T}<65^{\circ} \mathrm{C} \mathrm{m}=2.2, \mathrm{k}_{2}=\left(5.7 \times 10^{8} \mathrm{~min}^{-1}\right) \exp \left(-8000^{\circ} \mathrm{K} / \mathrm{T}\right)$

for $65<\mathrm{T}<90^{\circ} \mathrm{C} \quad \mathrm{k}_{2}=\left(9 \times 10^{7} \mathrm{~min}^{-1}\right) \frac{(90-\mathrm{T})}{\mathrm{T}^{6}} \quad\left[\mathrm{~T}\right.$ in $\left.{ }^{\circ} \mathrm{C}\right]$

$$
\mathrm{m}=74 \mathrm{k}_{2} \quad\left[\mathrm{k}_{2} \text { in } \mathrm{min}^{-1}\right]
$$

for $\mathrm{T}>90^{\circ} \mathrm{C} \mathrm{m}=\mathrm{k}_{2}=0$

$828 / \mathrm{Z}$ for $\mathrm{T} \leq 110^{\circ} \mathrm{C}$

$\frac{\mathrm{dp}}{\mathrm{dt}}=\mathrm{k}_{\mathrm{A}}\left(0.11+\mathrm{p}^{1.2}\right)(1-\mathrm{p})^{1.35}$

where $k_{A}=\left(1.2 \times 10^{6} \min ^{-1}\right) \exp [-(12 \mathrm{kcal} / \mathrm{mole}) / \mathrm{RT}]$

459 for $\mathrm{T} \leq 110^{\circ} \mathrm{C}$

$\frac{\mathrm{dp}}{\mathrm{dt}}=\mathrm{k}_{\mathrm{A}}(0.367+\mathrm{p})(1-\mathrm{p})^{1.5}$

where $k_{A}=\left(1.9 \times 10^{6} \min ^{-1}\right) \exp [-(12 \mathrm{kcal} / \mathrm{mole}) / \mathrm{RT}]$ 
Distribution

1

5

2

1

10

1

1

1

1

1

1

1

1

1

1

1

1
MS9018

0899

0619

0333

0333

0961

9404

0443

0443

0443

0343

0342

0515

0856

0958

0958

0958
Central Technical Files, 8523-2

Technical Library, 4414

Review \& Approval Desk, 12630 For DOE/OSTI

Al Hurd, 1841

Doug Adolf, 1841

John Sayre, 1403

Linda Domeier, 8713

Bob Chambers, 9517

Steve Burchett, 9517

Hal Morgan, 9517

Mike Keenan, 1824

Kim Mahin, 1807

Frank Bacon, 1561

Barb Wells, 14482

Howard Arris, 1472

Matt Donnelly, 1472

Ginger DeMarquis, 1472 